\title{
The Effect of Different Chemical Treatments on the Structure and Stability of Aqueous Dispersion of Iron- and Iron Oxide-Filled Multi-Walled Carbon Nanotubes
}

\author{
Rodrigo A. Moraes, ${ }^{a}$ Carolina F. Matos, ${ }^{a}$ Eryza G. Castro, ${ }^{a}$ Wido H. Schreiner, ${ }^{b}$ \\ Marcela M. Oliveira ${ }^{c}$ and Aldo J. G. Zarbin $*, a$
} ${ }^{a}$ Departamento de Química and ${ }^{b}$ Departamento de Física, Universidade Federal do Paraná,
CP 19081, 81531-990 Curitiba-PR, Brazil

'Departamento Acadêmico de Química e Biologia, Universidade Tecnológica Federal do Paraná, Av. Sete de Setembro 3165, 80230-901 Curitiba-PR, Brazil

\begin{abstract}
$\mathrm{O}$ efeito de cinco diferentes tratamentos químicos $\left(\mathrm{HNO}_{3}, \mathrm{H}_{2} \mathrm{SO}_{4}, \mathrm{H}_{2} \mathrm{O}_{2}, \mathrm{HNO}_{3}+\mathrm{H}_{2} \mathrm{SO}_{4} \mathrm{e}\right.$ $\mathrm{HNO}_{3}+\mathrm{HCl}$ ) na homogeneidade, superfície, estrutura e dispersabilidade em água de nanotubos de carbono do tipo multi-paredes preenchidos com ferro ou óxido de ferro foi estudado através de difratometria de raios X (XRD), espectroscopias Raman, UV-Visível e fotoeletrônica de raios X (XPS), análise termogravimétrica (TG) e microscopia eletrônica de varredura (MEV). Os resultados indicaram que os tratamentos são efetivos na remoção de espécies carbonáceas diferentes de nanotubos, presentes na amostra. Com exceção do tratamento com $\mathrm{H}_{2} \mathrm{O}_{2}$, uma boa remoção das espécies contendo metal também foi observada. Além de aumentar a homogeneidade das amostras, os tratamentos também criam grupos carboxílicos e hidroxílicos superficiais, que afetam diretamente a dispersabilidade destas espécies em água. Dispersões estáveis de $2,24 \times 10^{-1} \mathrm{~g} \mathrm{~L}^{-1} \mathrm{de}$ nanotubos em água foram obtidas após o tratamento com mistura de ácido sulfúrico e ácido nítrico.
\end{abstract}

The effect of five different chemical treatments $\left(\mathrm{HNO}_{3}, \mathrm{H}_{2} \mathrm{SO}_{4}, \mathrm{H}_{2} \mathrm{O}_{2}, \mathrm{HNO}_{3}+\mathrm{H}_{2} \mathrm{SO}_{4}\right.$ and $\mathrm{HNO}_{3}+\mathrm{HCl}$ ) on the homogeneity, surface chemistry, structure and dispersibility in water of ironand iron oxide-filled multi-walled carbon nanotube samples was evaluated by X-ray diffractometry (XRD), Raman, UV-Visible and X-ray photoelectron (XPS) spectroscopies, thermogravimetric analysis (TG) and scanning electron microscopy (SEM). The results indicate that the chemical treatments are generally effective in removing non-nanotube carbonaceous species present in the sample. With the exception of the $\mathrm{H}_{2} \mathrm{O}_{2}$ treatment, the chemical treatments also offer good removal of free iron-species. Besides the increase in the sample homogeneity, the chemical treatments promoted an increase in the carboxyl and hydroxyl groups at the carbon nanotube surface, what directly affects the dispersibility of these carbon nanotubes in water. Dispersions of $2.24 \times 10^{-1} \mathrm{~g} \mathrm{~L}^{-1}$ were obtained for the treated samples with a mixture of nitric and sulfuric acid.

Keywords: carbon nanotubes, chemical treatment, CVD, nanostructures, nanomaterials

\section{Introduction}

Carbon nanotubes (CNTs) have received much attention in the last years due to their extraordinary chemical and physical properties, arising from the combination of their typical morphology, structure and size. ${ }^{1}$ Many different processes have been described for the synthesis of CNTs. Among them, one of the most versatile is the catalytic chemical vapor deposition (CVD), which is based on the decomposition of a carbon source (usually a hydrocarbon)

*e-mail: aldozarbin@ufpr.br over metal nanocatalysts. ${ }^{2}$ Usually, the resulting samples are a mixture of CNTs and some impurities, such as other carbonaceous materials (graphite, amorphous carbon, fullerenes, carbon nano-structures, etc.) and the catalyst metal particles. ${ }^{3}$ These impurities are undesirable for a variety of applications, and different physical and/or chemical treatments are usually performed to remove them. ${ }^{4}$ However, it should be noted that these "impurities" do not interfere in a number of applications, and sometimes they even improve some properties.

The most common and widely used purification methods are based on oxidative treatments that are aimed 
at the selective oxidation of different types of carbonaceous structures, followed by acid treatment to remove the catalyst particles. ${ }^{5}$ For example, amorphous carbon is easily eliminated due to its high density of defects, which allow its oxidation under mild conditions (while CNTs are not themselves oxidized). The most difficult problem is related to the removal of graphite-like polyhedral particles whose oxidation rates are similar to that of CNTs. In addition, it is common to find metal catalyst particles that are encapsulated by layers of amorphous carbon and/or shells of graphite. It is noteworthy that these impurities present broad size distributions and different types of defects and curvatures, which hinder the development of unified and efficient methods for the purification of these materials. Moreover, any type of post-synthesis treatment on CNT samples must be carefully carried out to avoid further losses or structural changes in CNTs. The optimum conditions for the post-treatment of CNT samples are very specific for each type of sample (single- or multi-walled CNTs, preparation method, type of impurities and catalyst, etc.), what means that systematic studies are necessary to find those conditions.

Chemical treatments are also routinely employed to create functional groups on the surface of CNTs, resulting in functionalized CNTs. ${ }^{6}$ Several chemical modifications are carried out to obtain good and stable dispersions of nanotubes in different solvents. For example, the addition of carboxyl and hydroxyl groups on the surface of CNTs facilitates their homogeneous dispersion in polar media.? The good dispersibility of CNTs directly affects their processing, what is a very crucial step for several applications (e.g., in composites). Another widely used approach to stabilize the CNT dispersion is the utilization of different types of surfactants, polymers and proteins that physically adsorb onto the surface of CNTs and stabilize the dispersion through electrostatic repulsion.

The preparation of a stable CNT dispersion is not a trivial process, especially aqueous dispersions. Two types of competitive interactions influence the dispersibility of the nanotubes: van der Waals forces between CNTs and interactions between CNTs and their surroundings. ${ }^{8}$ Several approaches have been taken to improve the stability of a CNT dispersion, for example sonication, ${ }^{9}$ functionalization, ${ }^{10-12}$ use of surfactants, ${ }^{13-15}$ among many others. ${ }^{16,17}$ The quality of these dispersions are usually quantified by techniques such as absorption, fluorescence and Raman spectroscopies, ${ }^{18}$ as well as techniques like transmission electron microscopy (TEM), scanning electron microscopy (SEM) and atomic force microscopy (AFM). ${ }^{19,20}$ However, absorption spectroscopy in the ultraviolet-visible-near infrared (UV-Vis-NIR) range is described as the most accurate of these techniques. ${ }^{21,22}$ Individual CNTs exhibit characteristic absorption bands in the UV-Vis-NIR region that are attributed to the van Hove singularities for unidimensional structures. ${ }^{23}$ However, only few CNT electronic transitions are active in the range of 200 to $1200 \mathrm{~nm}$. These characteristics allow the establishment of a direct relationship between the quantity of individually dispersed nanotubes in solution and the intensity of the band in the absorption spectrum.

Recently, some of us have reported the synthesis and characterization of iron- and iron oxide-filled multi-walled carbon nanotubes (MWCNTs), which are based on the pyrolysis of pure ferrocene in a poor oxygen atmosphere. ${ }^{24}$ This is a very interesting and specific CNT sample because it presents magnetic properties due to the ironbased fillers..$^{25}$ The specific synergistic combination of the electrical and mechanical CNT-based properties and the optical and magnetic iron and iron oxide properties result in an unusual multifunctional material, which has been widely used in our research group as a gas sensor and in electrical memory devices, ${ }^{26}$ as a filler in organic photovoltaic devices, ${ }^{27}$ in conducting-polymers and metal nanoparticlebased nanocomposites, ${ }^{28,29}$ and in electrochemical electrodes..$^{30}$ For many of these applications, specific chemical treatments must be performed first in order to remove impurities, add functionalities and/or stabilize the CNT dispersion. In this paper, we describe the effect of five different chemical treatments on the composition, structure and aqueous dispersibility of the iron- and iron oxide-filled MWCNT sample. Although several articles have been recently published focusing on the different chemical treatment of CNTs, ${ }^{3-5,31}$ there are no systematic data on the effect of these chemical treatment methods on metal-filled CNT samples.

\section{Experimental}

\section{Materials}

Nitric acid (Carlo Erba), sulfuric acid (Merck), hydrochloric acid (Vetec), sodium dodecyl sulphate (Aldrich) and a $30 \mathrm{wt} . \%$ solution of hydrogen peroxide (Vetec) were used as received. Water was deionized using a Milli-Q Ultra-Pure-Water Purification System. Ferrocene (Fluka) was purified by sublimation before the use. Pristine iron- and iron oxide-filled MWCNTs were synthesized by CVD, starting from pure ferrocene according to our previous report. ${ }^{24}$ Typically, a quartz tube $(36 \mathrm{~mm}$ in diameter and $750 \mathrm{~mm}$ in length) was placed in a two-stage furnace system, and argon (99\% purity) was passed through the tube. The purified ferrocene was placed inside the first 
furnace and sublimed by raising the temperature of this furnace to $300{ }^{\circ} \mathrm{C}$. The vapor was carried by the argon flow into the second furnace maintained at $900{ }^{\circ} \mathrm{C}$. After $2 \mathrm{~h}$, the furnace system was turned off. The pyrolysis yielded large amounts of carbon deposited in the quartz tube wall inside the second furnace. The most uniform sample was obtained in the center of the second furnace. However, in this work, it was collected the product that was produced in all furnace regions. This pristine sample is referred to here as p-CNT.

\section{Chemical treatment}

The chemical treatments were performed by adding $15 \mathrm{mg}$ of p-CNT in $40 \mathrm{~mL}$ of five different aqueous solutions $\left(\mathrm{H}_{2} \mathrm{O}_{2}\right.$ $31 \mathrm{wt} \%, \mathrm{HNO}_{3} 3 \mathrm{~mol} \mathrm{~L}^{-1}$, a mixture (1:1 in volume) of $\mathrm{HNO}_{3}$ $3 \mathrm{~mol} \mathrm{~L}^{-1}+\mathrm{HCl} 1 \mathrm{~mol} \mathrm{~L}^{-1}, \mathrm{H}_{2} \mathrm{SO}_{4} 3 \mathrm{~mol} \mathrm{~L}^{-1}$ and a mixture ( $1: 1$ in volume) of $\mathrm{H}_{2} \mathrm{SO}_{4} 3 \mathrm{~mol} \mathrm{~L}{ }^{-1}+\mathrm{HNO}_{3} 3 \mathrm{~mol} \mathrm{~L}{ }^{-1}$ ). The mixtures were heated and maintained under reflux for $6 \mathrm{~h}$ (except for the $\mathrm{H}_{2} \mathrm{O}_{2}$ solution in which the reflux was maintained for $2 \mathrm{~h}$ ). After this time, the insoluble powder was separated by centrifugation, washed several times with deionized water (until neutral $\mathrm{pH}$ ) and dried under air at $40^{\circ} \mathrm{C}$. The samples is referred to here as CNT/HP ( $\mathrm{HP}=$ hydrogen peroxide $), \mathrm{CNT} / \mathrm{NA}(\mathrm{NA}=$ nitric acid $)$, $\mathrm{CNT} / \mathrm{NA}+\mathrm{CA}(\mathrm{CA}=$ hydrochloric acid $), \mathrm{CNT} / \mathrm{SA}$ (SA = sulfuric acid) and CNT/SA+NA for the samples that were treated with hydrogen peroxide, nitric acid, a mixture of nitric and hydrochloric acids, sulfuric acid and a mixture of sulfuric and nitric acid, respectively.

\section{Aqueous dispersion of CNTs}

In order to prepare an aqueous dispersion of pristine and treated-CNTs, an amount of $1.2 \mathrm{mg}$ of CNTs was mixed in $4.0 \mathrm{~mL}$ of water, and the mixture was placed in an ultrasound bath (UNIQUE-USC 1880, $154 \mathrm{~W}$ - delivering $9240 \mathrm{~J} \mathrm{~min}^{-1}$ ). The effects of the sonication time and energy on the stability of the dispersion were evaluated using $4.0 \mathrm{~mL}$ of $0.3 \mathrm{~g} \mathrm{~L}^{-1}$ of CNT dispersions, by monitoring the intensity of the absorption band at $260 \mathrm{~nm}$ (characteristic of de-bundled CNTs). The effect of the surfactant sodium dodecylsulfate (SDS) was also studied. In this case, an amount of $1.8 \mathrm{mg}$ of SDS (SDS/CNTs ratio of 1:1.5 in weight) was added to the aqueous dispersion of CNTs before the sonication.

The amount of CNTs that was effectively dispersed was gravimetrically evaluated in triplicate. A $4.0 \mathrm{~mL}$ aliquot of $0.3 \mathrm{~g} \mathrm{~L}^{-1}$ of CNT suspension was sonicated for $2 \mathrm{~h}$, and then centrifuged at $2000 \mathrm{rpm}$ for $5 \mathrm{~min}$. The supernatant was subsequently removed, and the precipitate dried in an oven at $120{ }^{\circ} \mathrm{C}$ for $24 \mathrm{~h}$, cooled at room temperature and weighed. The effective amount of dispersed CNTs in each solution was estimated by the subtraction of the initial weight of the used CNTs to prepare the dispersion and the weight of the separated CNTs by centrifugation.

The stability of each CNT dispersion was evaluated for $120 \mathrm{~h}$ by measuring the intensity of the absorption band at $260 \mathrm{~nm}$ in specific intervals.

\section{Characterization}

The Raman spectra were obtained in a Renishaw Raman Image spectrophotometer coupled to an optical microscope that focused the incident radiation down to a spot of ca. $1 \mu \mathrm{m}$. A He-Ne laser $(632.8 \mathrm{~nm})$ was used with an incidence power of $10 \mathrm{~mW}$ over the $3000-200 \mathrm{~cm}^{-1}$ range.

$\mathrm{X}$-ray diffraction (XRD) measurements were performed in a Shimadzu XD-3A diffractometer using $\mathrm{Cu} \mathrm{K}_{\alpha}$ radiation, $40 \mathrm{kV}, 40 \mathrm{~mA}$, at a scan rate of 0.02 (in $2 \theta$ / degree) and a step of $10 \mathrm{~s}$ per point. Powder silicon reflections were used for $2 \theta$ calibration.

$\mathrm{X}$-ray photoelectron spectroscopy (XPS) experiments were performed using a commercial system (VG Microtech ESCA3000 equipped with $\mathrm{Mg} \mathrm{K}_{\alpha}$ and $\mathrm{Al} \mathrm{K}_{\alpha}$ radiation sources) with a base pressure of $3 \times 10^{-10} \mathrm{mbar}$. The spectra were obtained at a takeoff angle of $45^{\circ}$ (normal) using a hemispherical energy analyzer with an overall energy resolution of $c a$. $0.8 \mathrm{eV}$. The binding energy scales were referenced by setting the $\mathrm{C} 1 \mathrm{~s}$ binding energy to $285.0 \mathrm{eV}$. The XPS analyses were performed by assuming core level spectra with Gaussian line shapes after standard Shirley background subtraction. Samples were prepared by dispersion on an aluminum sample holder prior to each experiment.

Thermogravimetric analyses (TG) were carried out in SDT Q600 equipment (TA Instruments) under an atmosphere of synthetic air (White Martins, $100 \mathrm{~mL} \mathrm{~min}^{-1}$ ) at a heating rate of $5{ }^{\circ} \mathrm{C} \mathrm{min}{ }^{-1}$ from room temperature to $400{ }^{\circ} \mathrm{C}$ and scan rate of $2{ }^{\circ} \mathrm{C} \mathrm{min}{ }^{-1}$ from 400 to $900{ }^{\circ} \mathrm{C}$.

Scanning electron microscopy (SEM) images were obtained from deposited samples over a metal substrate using a Jeol JSM 6360 LV microscope.

UV-Visible spectra were collected from the aqueous dispersion of CNTs in a Shimadzu UV-2450 spectrophotometer, using air as reference, in the range of 190-900 nm.

\section{Results and Discussion}

The studied pristine material in this work is, in fact, a mixture of MWCNTs, amorphous carbon, graphite 
nanopolyhedra and different iron-based compounds, mainly encapsulated by different carbonaceous species, as previously described. ${ }^{24}$ The obtained black deposit in all the quartz tube extension was deliberately mixed (in spite of our previous knowledge that the materials are different in each tube region) in order to obtain the "dirtiest" sample and verify the effect of the chemical treatment on it.

Figure 1 contains the normalized X-ray diffractograms of the samples, showing the occurrence of the $\mathrm{d}_{002}$ peaks (d ca. $0.34 \mathrm{~nm}$ ) characteristic of MWCNTs, as well as several other diffraction peaks from iron-based compounds (mainly $\alpha-\mathrm{Fe}, \alpha-\mathrm{Fe}_{2} \mathrm{O}_{3}$ (hematite), $\mathrm{Fe}_{3} \mathrm{O}_{4}$ (magnetite) and $\mathrm{Fe}_{3} \mathrm{C}$ (cementite)). In order to perform a comparison between the amount of carbonaceous and ferrous materials present in the pristine sample and in those obtained after chemical treatment, the ratio between the intensity of the peak at $2 \theta=26.24$ (due to the (002) planes of graphiticlike carbon, marked with a \# in Figure 1) and the peak at $2 \theta=44.72$ (due to the (100) planes of $\alpha-F e$, market with $\mathrm{a} *$ in Figure 1) $\left(\mathrm{C}_{(002)} / \mathrm{Fe}_{(100)}\right.$ ratio) was calculated. The values are shown in Table 1. As can be seen, except for the $\mathrm{H}_{2} \mathrm{O}_{2}$-treated sample, the acid treatment promoted an

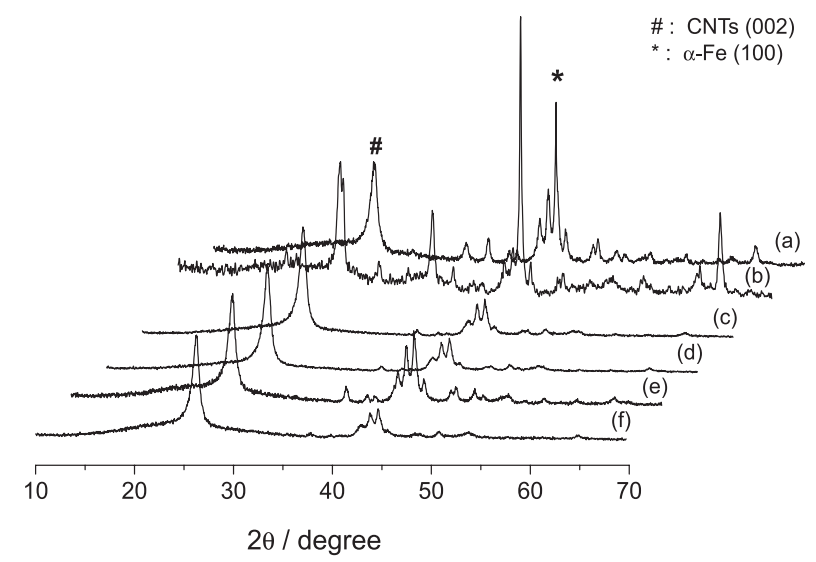

Figure 1. X-ray diffractograms of pristine carbon nanotubes (a) and for carbon nanotubes after the chemical treatments: (b) hydrogen peroxide (CNT/HP), (c) nitric acid (CNT/NA), (d) nitric + hydrochloridric acid (CNT/NA+CA), (e) sulfuric acid (CNT/SA) and (f) sulfuric + nitric acid (CNT/SA+NA). increase in the $\mathrm{C}_{(002)} / \mathrm{Fe}_{(100)}$ ratio, suggesting that a fraction of the iron species present in the samples was removed. According to the XRD data, the treatment with a mixture of $\mathrm{H}_{2} \mathrm{SO}_{4}$ and $\mathrm{HNO}_{3}$ was the most efficient to remove the metallic species. It is believed that the originally capped metallic species by carbonaceous structures are dissolved and removed during the washing steps. Some acidic solutions become pale yellow after the treatment, confirming this hypothesis.

The significant decrease in the $\mathrm{C}_{(002)} / \mathrm{Fe}_{(100)}$ ratio in the $\mathrm{H}_{2} \mathrm{O}_{2}$-treated sample indicates that a large amount of carbonaceous structure was removed. It is believed that the presence of a high amount of iron species (including $\mathrm{Fe}(\mathrm{II})$ in magnetite) aids in the process of carbon oxidation by $\mathrm{H}_{2} \mathrm{O}_{2}$. Several works have shown that the presence of iron-based particles has a large influence on the oxidation of amorphous carbon because these particles act as catalysts on the so-called Fenton reaction, ${ }^{32}$ producing the powerful oxidant hydroxyl radical $(\bullet \mathrm{OH})$.

Figure 2 shows the thermogravimetric data for the samples. From the thermogravimetric data, it is possible to obtain both the oxidation temperature $\left(\mathrm{T}_{\mathrm{o}}\right)$ (defined as the maximum peak temperature in the DTG curve $\left.\left(\mathrm{dm} / \mathrm{dT}_{\text {max }}\right)\right)$ and the content of residue $\left(\mathrm{M}_{\mathrm{res}}\right)$ remaining after the oxidation process. The presence of multiple-components in the sample (nanotubes, amorphous carbon and graphitic nanoparticles) can be also detected by the presence of more than one peak in the DTG curve..$^{33}$ The obtained data from the TG and DTG curves are summarized in Table 1.

The TG curve of the p-CNT sample (Figure 2a) presents a large and asymmetric DTG peak at $400-600^{\circ} \mathrm{C}$ which is associated with a oxidation event and can be deconvoluted in three Lorentzian peaks, confirming the occurrence of different carbonaceous structures in the samples. The medium $\mathrm{T}_{\mathrm{o}}$ value for this sample is $496^{\circ} \mathrm{C}$, although the three peaks in the DTG can be associated to three different carbonaceous structures with $\mathrm{T}_{0}$ at 433 , 456 and $496{ }^{\circ} \mathrm{C}$, respectively. The $41 \mathrm{wt} . \%$ of the residue that remain at $800^{\circ} \mathrm{C}$ are due to the iron-species present

Table 1. Some data obtained from XRD, Raman spectroscopy, XPS and TG for the iron- and iron oxide-filled carbon nanotubes before and after the chemical treatments

\begin{tabular}{|c|c|c|c|c|c|c|}
\hline Sample & $\begin{array}{c}\mathrm{XRD} \\
\mathrm{C}_{(002)} / \mathrm{Fe}_{(100)} \text { ratio }\end{array}$ & $\begin{array}{c}\text { Raman } \\
\mathrm{I}_{\mathrm{D}} / \mathrm{I}_{\mathrm{G}} \text { ratio }\end{array}$ & $\begin{array}{c}\text { Raman } \\
\mathrm{I}_{\mathrm{D}}, / \mathrm{I}_{\mathrm{G}} \text { ratio }\end{array}$ & $\begin{array}{c}\% \mathrm{C} \mathrm{sp}{ }^{2} \\
\text { XPS }\end{array}$ & $\begin{array}{c}\mathrm{TG} \\
\mathrm{T}_{\text {oxid }} /{ }^{\circ} \mathrm{C}\end{array}$ & $\begin{array}{c}\text { TG } \\
\text { residue / \% }\end{array}$ \\
\hline $\mathrm{p}-\mathrm{CNT}$ & 1.07 & 0.79 & 0.10 & 72.1 & 496 & 41 \\
\hline $\mathrm{CNT} / \mathrm{HP}$ & 0.45 & 1.52 & 0.15 & 35.6 & 632 & 59 \\
\hline CNT/NA & 2.30 & 1.05 & 0.15 & 51.1 & 522 & 16 \\
\hline $\mathrm{CNT} / \mathrm{NA}+\mathrm{CA}$ & 2.28 & 0.74 & 0.15 & 54.2 & 530 & 15 \\
\hline $\mathrm{CNT} / \mathrm{SA}$ & 1.45 & 0.68 & 0.10 & 72.1 & 566 & 27 \\
\hline $\mathrm{CNT} / \mathrm{SA}+\mathrm{NA}$ & 3.00 & 1.13 & 0.14 & 46.6 & 560 & 14 \\
\hline
\end{tabular}



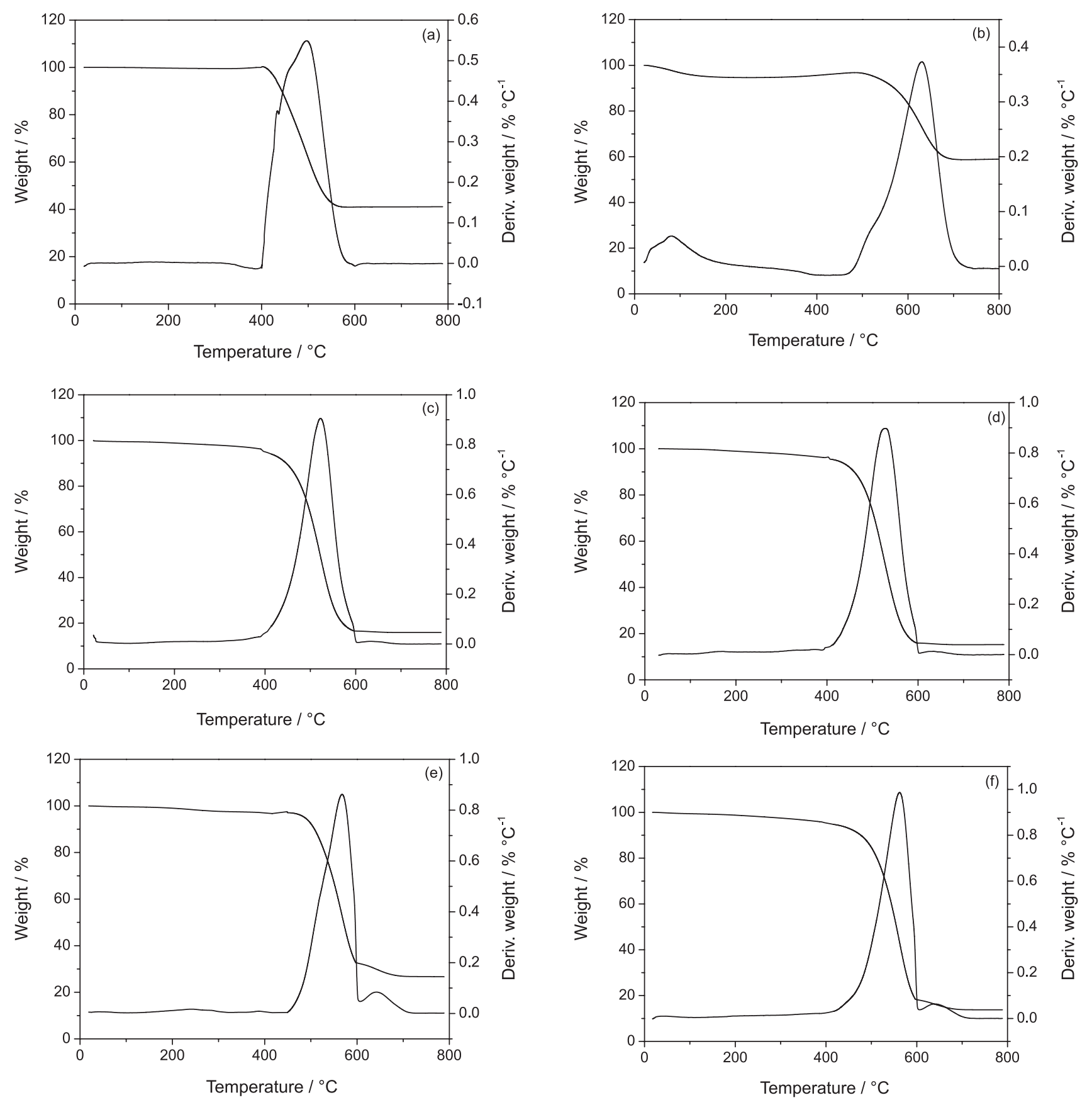

Figure 2. TG and DTG curves of pristine carbon nanotubes (a) and carbon nanotubes after the chemical treatments: (b) hydrogen peroxide (CNT/HP), (c) nitric acid (CNT/NA), (d) nitric + hydrochloridric acid (CNT/NA+CA), (e) sulfuric acid (CNT/SA) and (f) sulfuric + nitric acid (CNT/SA+NA).

in the sample. After the chemical treatments, $\mathrm{T}_{\mathrm{o}}$ of all samples increased (see Table 1) and the DTG peak become more symmetric and sharp, indicating more homogeneous samples. This effect is attributed to the removal of other forms of thermally unstable carbon that decompose at temperatures below $500{ }^{\circ} \mathrm{C} .1,5,34$ The increase in $\mathrm{T}_{\mathrm{o}}$ of all samples indicates that the disordered carbon, which is oxidized at lower temperatures, was removed from the samples after the chemical treatment. The full width at half maximum (FWHM) of the DTG peak is an indicative of the sample homogeneity (a lower FWHM indicates a sharper and more discrete event, characteristic of more uniform sample). After the chemical treatments, all samples (except for CNT/SA) presented a single DTG peak. FWHMs were 226, 104, 79, 87, 98 and $75^{\circ} \mathrm{C}$ for p-CNT, CNT/HP, CNT/NA, CNT/NA+CA, CNT/SA and CNT/SA+NA samples, respectively, indicating that the nitric acid treatment (both pure or mixed with sulfuric acid) is a better treatment to remove non-nanotube species from $\mathrm{p}-\mathrm{CNT}$. 
In which concerns the amount of remaining residues after the different treatments, the obtained results by TG agree with those observed by XRD: $i$ ) the amount of residues increased after treatment with $\mathrm{H}_{2} \mathrm{O}_{2}(59$ wt. $\%$ vs. 41 wt. \% of the p-CNT), corroborating the XRD data and confirming that only the non-nanotube carbon was removed by the $\mathrm{H}_{2} \mathrm{O}_{2}$ treatment. This means that the $\mathrm{C} /$ metallic species ratio in the sample decreased (as observed by XRD), resulting in a higher amount of remaining residue after the air oxidation of the carbonaceous compounds; $i i$ ) the amount of residues decreased after the acidic treatments $(16,15,27$ and 14 wt. \% for samples CNT/NA, CNT/NA+CA, CNT/SA and $\mathrm{CNT} / \mathrm{SA}+\mathrm{NA}$, respectively). This means that part of the metallic species in the samples was removed. It is interesting that the TG data clearly show that the mixture of nitric and sulfuric acids was the best treatment for the removal of both the metallic species (again in accordance with the XRD data) and the amorphous carbon. This coincidence indicates that, as expected, the attacked metallic species by the acid correspond to the metallic fraction that was originally capped by the easily oxidized carbonaceous structure. This becomes unprotected after the carbon oxidation. It is important to notice that the amount of residues remained the same for obtained samples with prolonged reaction times (see Figure S1, Supplementary Information). This confirms that $6 \mathrm{~h}$ of treatment are enough under the experimental conditions that are here reported.

Finally, it is interesting to observe that all the chemically treated samples presented a small and continuous weightloss ( $c a .8 \mathrm{wt} . \%$ ) starting at $c a .150^{\circ} \mathrm{C}$ and detectable until the beginning of the oxidation process at $c a .405^{\circ} \mathrm{C}$. This weight loss is attributed to the decomposition of grafted functional groups that were created on the surface of the carbonaceous materials after the chemical treatment.

The normalized Raman spectra of the samples are shown in Figure 3. The spectra consist of four well-known and characteristic CNT bands: ${ }^{35-37} 1578 \mathrm{~cm}^{-1}$ ( $\mathrm{G}$ band, attributed to in-plane C-C symmetric stretching vibrations in graphene sheets), $1335 \mathrm{~cm}^{-1}$ (D band, usually attributed to the presence of disordered carbon, as well as to the structural disorder, such as defective rings, presence of heteroatoms, dangling bond and vacancies, present in the graphene sheet), $2655 \mathrm{~cm}^{-1}$ (G' or 2D band, a second order band that is an overtone of the $\mathrm{D}$ band) and a weak shoulder at higher frequencies of the G-band at $1612 \mathrm{~cm}^{-1}$ (D' band, a double resonance feature also induced by the presence of disorder and defects). The ratio between the $\mathrm{D}$ and $\mathrm{G}$ bands $\left(\mathrm{I}_{\mathrm{D}} / \mathrm{I}_{\mathrm{G}}\right)$ as well as between the D' and $\mathrm{G}$ bands $\left(\mathrm{I}_{\mathrm{D}}, / \mathrm{I}_{\mathrm{G}}\right)$, can be used to estimate the degree of structural disorder and/or amorphous compounds in $\mathrm{sp}^{2}$-based carbons. ${ }^{38}$ Both the $\mathrm{I}_{\mathrm{D}} / \mathrm{I}_{\mathrm{G}}$ and $\mathrm{I}_{\mathrm{D}} / \mathrm{I}_{\mathrm{G}}$ values for samples are shown in Table 1. It is noticeable that the intensity of both $\mathrm{D}$ and D' bands increased after the chemical treatment, except for the $\mathrm{H}_{2} \mathrm{SO}_{4}$-treated sample. Comparing the different samples, a higher $\mathrm{I}_{\mathrm{D}} / \mathrm{I}_{\mathrm{G}}$ ratio was found for the $\mathrm{H}_{2} \mathrm{O}_{2}$-treated CNTs (1.52 vs. 0.79 for the p-CNTs), followed by the treated sample with a mixture of $\mathrm{H}_{2} \mathrm{SO}_{4}$ and $\mathrm{HNO}_{3}$ (1.13). According to the XRD and TG data previously discussed, these two treatments are more efficient at the removal of amorphous carbon. The increase in the $\mathrm{I}_{\mathrm{D}} / \mathrm{I}_{\mathrm{G}}$ values can be attributed to the creation of defects in the $\mathrm{sp}^{2}$ network of the CNT walls. This was confirmed by XPS (as will be discussed further) and is an expected result because it corresponds to the most oxidative treatments.

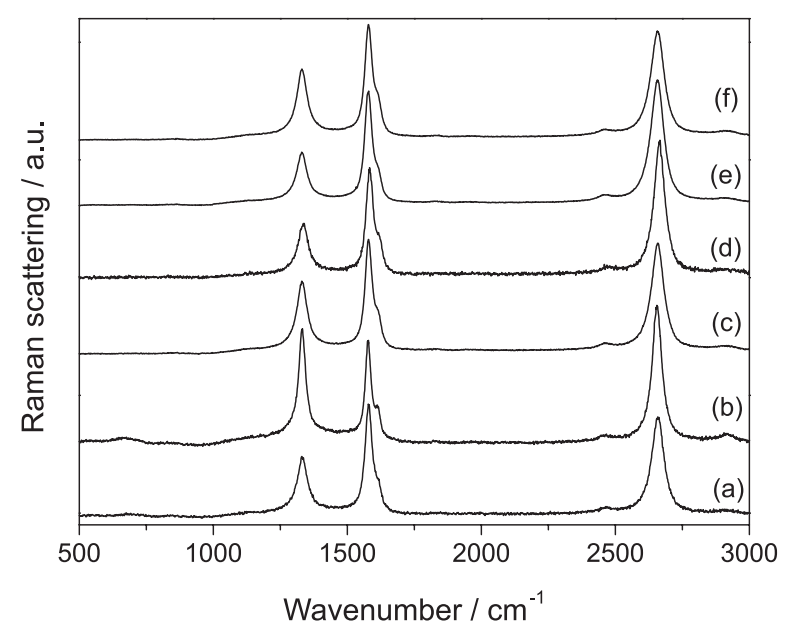

Figure 3. Raman spectra of pristine carbon nanotubes (a) and carbon nanotubes after the chemical treatments: (b) hydrogen peroxide (CNT/HP), (c) nitric acid (CNT/NA), (d) nitric + hydrochloridric acid (CNT/NA+CA), (e) sulfuric acid (CNT/SA) and (f) sulfuric + nitric acid (CNT/SA+NA).

The $\mathrm{I}_{\mathrm{D}} / \mathrm{I}_{\mathrm{G}}$ ratio was found to be lower in the $\mathrm{H}_{2} \mathrm{SO}_{4}$-treated sample than in the non-treated sample. This is likely due to the fact that the sulfuric acid treatment can remove part of the non-nanotube carbon (as observed by both XRD and TG data), but it cannot oxidize the walls of the remaining CNTs (also confirmed by XPS data, as will be further discussed). The increase in the $\mathrm{I}_{\mathrm{D}} / \mathrm{I}_{\mathrm{G}}$ ratio is only related to the decrease of disordered carbon in the sample with no damage on the CNT walls.

XPS is a very useful surface analysis technique that can provide information on the type of functional groups and presence of structural defects on the CNT walls. Figure 4 presents the XPS C1s spectra of CNTs before and after chemical treatment. All the Gaussian deconvoluted spectra show a main peak at $284.4 \mathrm{eV}$ which is attributed to a $\mathrm{sp}^{2}$-carbon in graphitic structure..$^{39,40}$ The low intensity peaks at higher binding energies ( 285.7 and $289.3 \mathrm{eV}$ ) are attributed to sp ${ }^{3}$-hybridized carbon atoms at the CNT surface. These carbon atoms are directly bond to functional groups such 

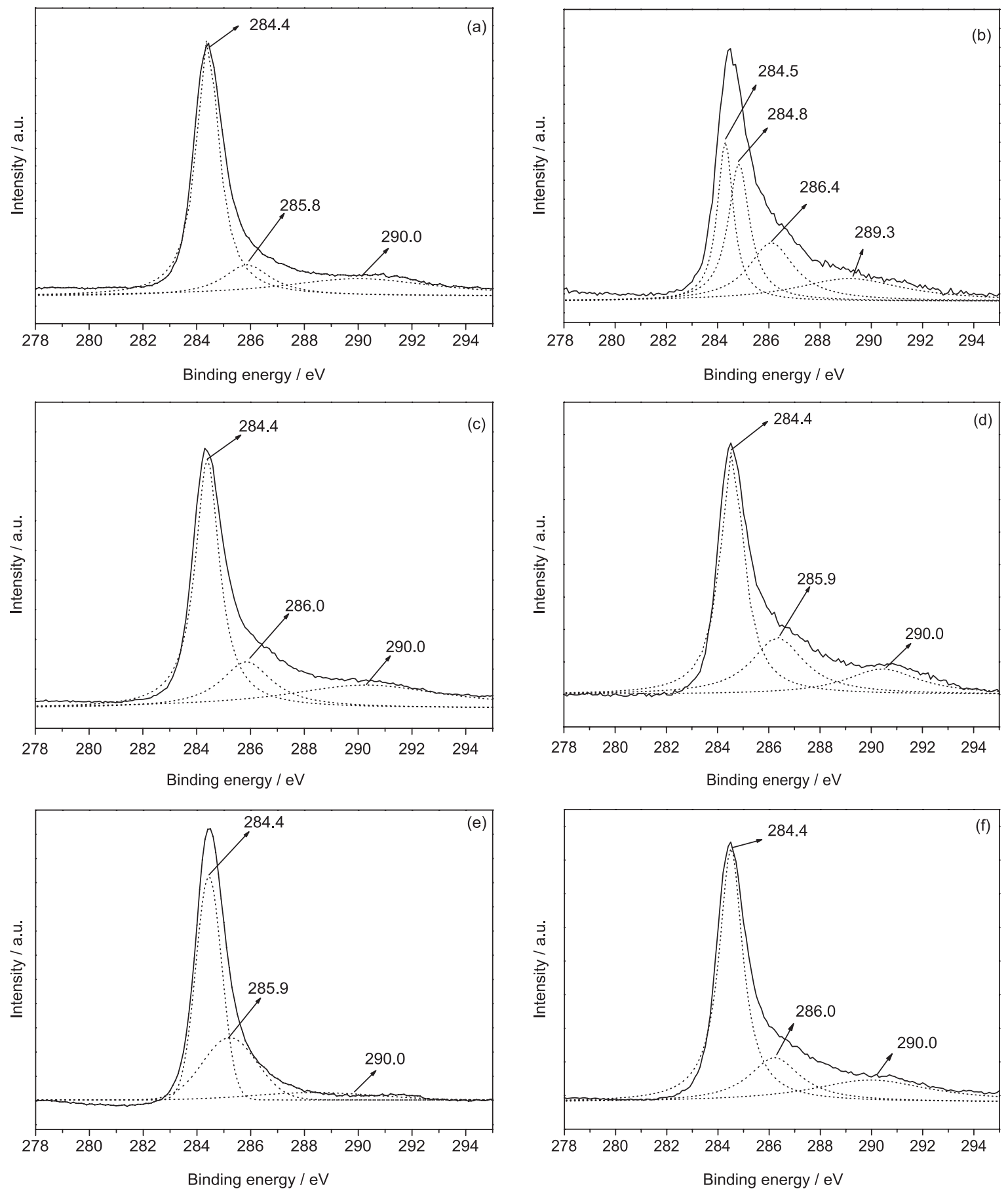

Figure 4. XPS spectra of pristine carbon nanotubes (a) and carbon nanotubes after the chemical treatments: (b) hydrogen peroxide (CNT/HP), (c) nitric acid (CNT/NA), (d) nitric + hydrochloridric acid (CNT/NA+CA), (e) sulfuric acid (CNT/SA) and (f) sulfuric + nitric acid (CNT/SA+NA).

as carboxylic acid and hydroxyl groups, ${ }^{41}$ whose amount increased notably after the chemical treatment. The relative amounts of $\mathrm{sp}^{2}$ and $\mathrm{sp}^{3}$ carbon atoms were evaluated from the corresponding XPS peak areas and the ratio found after the chemical treatments are listed in Table 1. As expected, the amount of $\mathrm{sp}^{3}$ carbon (and subsequently the amount of surface functional groups) is higher for the samples treated with $\mathrm{H}_{2} \mathrm{O}_{2}$ and a mixture of $\mathrm{HNO}_{3}$ and $\mathrm{H}_{2} \mathrm{SO}_{4}$.
Figures 5 and 6 show the SEM images of the p-CNTs and the obtained samples after the chemical treatments. The $\mathrm{p}-\mathrm{CNT}$ is a heterogeneous sample that is mainly composed of MWCNTs, as can be seen in Figures 5a and 5b. Other structures such as spherical aggregates and plates can be clearly seen in the images, corresponding to amorphous carbon, graphitic structures and non-encapsulated ironbased species. A noticeable decrease in the fraction of 

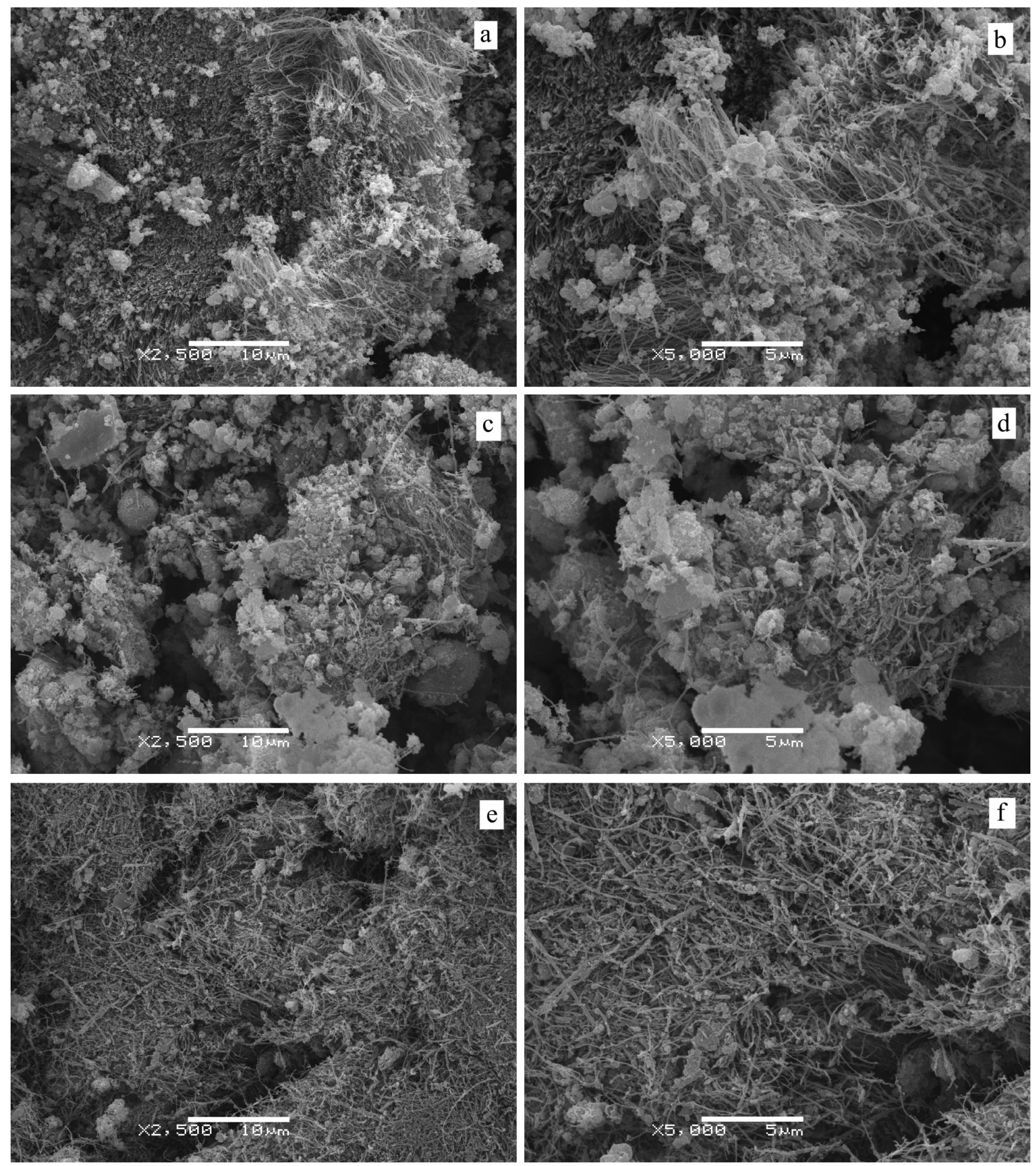

Figure 5. SEM images for (a) and (b) pristine CNTs, (c) and (d) CNTs treated with hydrogen peroxide (CNT/HP), (e) and (f) CNTs treated with nitric acid (CNT/NA). Scale bar is $10 \mu \mathrm{m}$ (left images) and $5 \mu \mathrm{m}$ (right images).

CNTs is observed in the sample after $\mathrm{H}_{2} \mathrm{O}_{2}$ treatment (Figures $5 \mathrm{c}$ and $5 \mathrm{~d}$ ). The CNT/HP sample is rich in nonnanotube species (mainly large plates) corresponding to the iron-based species, as observed by XRD and TG data. All acid treatments produced the most homogeneous and nanotube-rich samples (Figures $5 e, 5 f$ and 6 ), with a significant removal of the non-nanotube species.
As previously mentioned, the preparation of stable aqueous dispersions of CNTs is considered a prerequisite for several practical applications. So, it was conducted some experiments aiming stable aqueous dispersion of the samples p-CNT, CNT/HP and CNT/SA+NA. The effect of the addition of the surfactant SDS on the preparation and stability of an aqueous dispersion of 

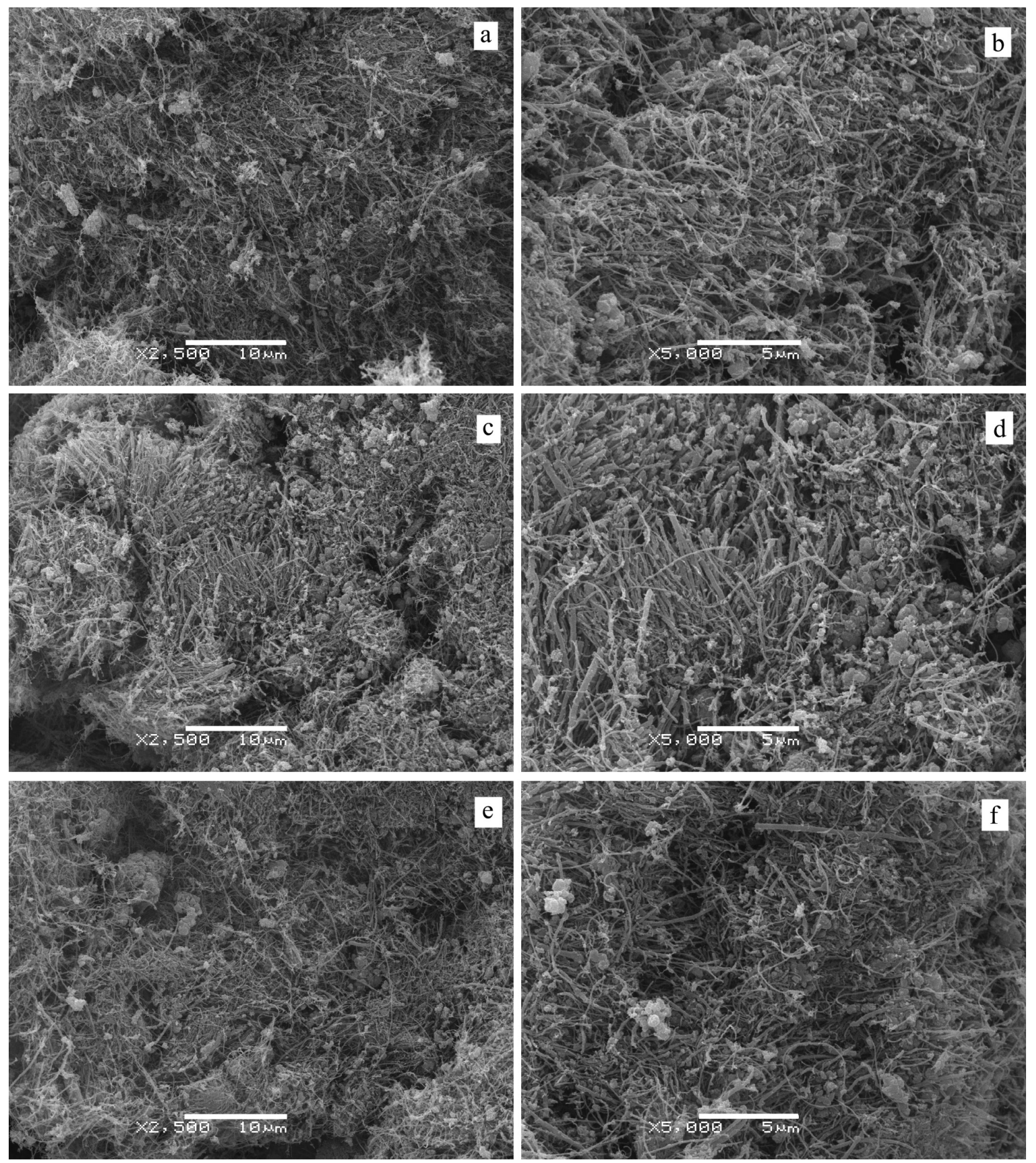

Figure 6. SEM images: (a) and (b) CNTs treated with a mixture of nitric and hydrochloridric acid (CNT/NA+CA), (c) and (d) CNTs treated with sulfuric acid (CNT/SA), (e) and (f) CNTs treated with a mixture of sulfuric and nitric acid (CNT/SA+NA). Scale bar is $10 \mu \mathrm{m}$ (left images) and $5 \mu \mathrm{m}$ (right images)

these three CNT samples was studied. The first step was to evaluate the evolution of the CNT dispersions during sonication. Figure 7 illustrates the UV-Vis spectra of a $0.3 \mathrm{~g} \mathrm{~L}^{-1}$ dispersion of $\mathrm{p}-\mathrm{CNTs} / \mathrm{SDS}$ in water at different sonication times. All spectra presented a typical absorption band at $260 \mathrm{~nm}$, which is attributed to a $\pi-\pi^{*}$ transition characteristic of MWCNTs. ${ }^{42}$ The provided mechanical energy by the ultrasound breaks the van der Waals interactions between CNTs, promoting the CNT dispersion. This results in an increase in the intensity of the absorption band (at $260 \mathrm{~nm}$ ) in the UV-Vis spectrum. It is clear from the spectra presented in Figure 7 that better dispersions can be achieved after $20 \mathrm{~min}$ of sonication $(184.8 \mathrm{~kJ})$, with the best value being reached after $120 \mathrm{~min}(1.1 \mathrm{MJ})$. 
Similar trends were found for other dispersions, showing that the needed sonication time to reach the best dispersion is $120 \mathrm{~min}(1.1 \mathrm{MJ})$. After this time, the maximum amount of CNTs that can be effectively dispersed was found to be $4.7 \times 10^{-2}, 2.17 \times 10^{-1}, 2.24 \times 10^{-1}, 2.03 \times 10^{-1}$, $9.0 \times 10^{-2}$ and $1.34 \times 10^{-1} \mathrm{~g} \mathrm{~L}^{-1}$ for the $\mathrm{p}-\mathrm{CNTs}, \mathrm{CNT} / \mathrm{HP}$, $\mathrm{CNT} / \mathrm{SA}+\mathrm{NA}, \mathrm{p}-\mathrm{CNT} / \mathrm{SDS}, \mathrm{CNT} / \mathrm{HP} / \mathrm{SDS}$ and $\mathrm{CNT/SA+NA/SDS} \mathrm{samples,} \mathrm{respectively.}$

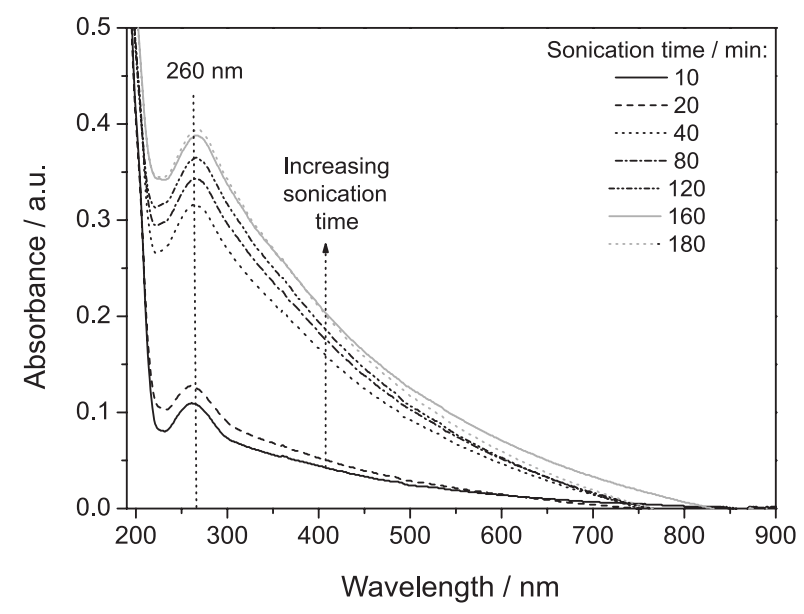

Figure 7. UV-Vis spectra of a $0.3 \mathrm{~g} \mathrm{~L}^{-1}$ aqueous dispersion of pristine CNTs in presence of the surfactant SDS, as a function of sonication time.

In order to achieve stability of the CNT dispersion, saturated dispersions were prepared, and the absorbance at $260 \mathrm{~nm}$ was monitored for $120 \mathrm{~h}$. The data are presented in Figure 8. It is clear that the prepared dispersions from p-CNTs present very low stability. Moreover, the chemical modifications provide significant improvement in dispersibility, especially the modification that was performed by the treatment with a mixture of nitric and sulfuric acids. The addition of SDS enhanced further the dispersibility and the stability of p-CNTs and CNT-NA+SA

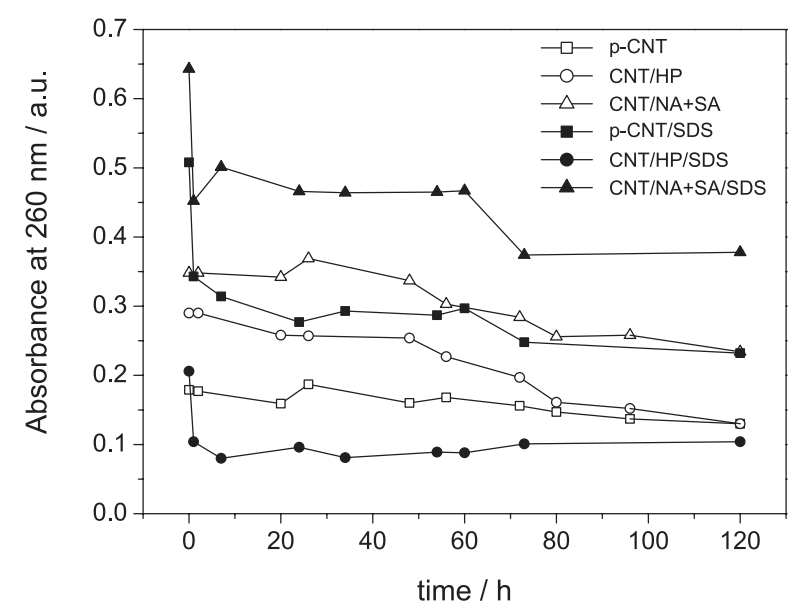

Figure 8. Time dependence of the absorbance (at $260 \mathrm{~nm}$ ) of the different dispersions of carbon nanotubes. dispersions. However, the presence of SDS has the opposite effect in the CNT/HP dispersion. It is believed that this behavior is due to the high degree of carboxyl and hydroxyl groups that are present on the surface of the nanotubes after the $\mathrm{H}_{2} \mathrm{O}_{2}$-based treatment. The excess of polar groups on the surface of CNTs suppresses the coating of CNTs by the non-polar fraction of the surfactant and increases the interaction with the polar fraction of SDS. This leaves the hydrophobic fraction of SDS in contact with water, decreasing the CNT-solvent interaction and resulting in the precipitation of CNTs.

According to the results shown in Figure 8, the best stability after $120 \mathrm{~h}$ was found in dispersions from the $\mathrm{CNT} / \mathrm{SA}+\mathrm{NA}, \mathrm{p}-\mathrm{CNT} / \mathrm{SDS}$ and CNT/SA+NA/SDS samples, which maintained 95,60 and $65 \%$ of the initial amount of dispersed CNTs, respectively.

\section{Conclusions}

This work reports, for the first time, the effect of five different chemical treatments on the modification of ironand iron oxide-filled MWCNTs. Data from techniques such as XRD, Raman, XPS and SEM showed that the treatment with an aqueous mixture of sulfuric and nitric acids results in a more homogeneous sample that produces the most stable aqueous dispersion. This treatment facilitates the elimination of non-nanotube carbonaceous materials and encapsulated iron species, yielding MWCNTs filled by iron species and containing carboxyl and hydroxyl functional groups on the surface.

\section{Supplementary Information}

TG curves of carbon nanotubes after chemical treatment (CNT/SA+NA) for 6 and $10 \mathrm{~h}$ are available free of charge as PDF file at http://jbcs.sbq.org.br.

\section{Acknowledgments}

We gratefully acknowledge the financial support of Conselho Nacional de Desenvolvimento Científico e Tecnológico (CNPq), Coordenação de Aperfeiçoamento de Pessoal de Nível Superior (CAPES-PROCAD), Núcleo de Excelência em Nanoquímica e Nanomateriais (NENNAM, PRONEX Fundação Araucária/CNPq Proc. 17378), the Brazilian Network on Carbon Nanotubes Research (CNPq) and Instituto Nacional de Ciências e Tecnologia (INCT-Nanocarbon, MCT/CNPq). We also thank LME-UFPR for the SEM images. C. F. M. thanks $\mathrm{CNPq}$ for a fellowship. 


\section{References}

1. Dresselhaus M. S.; Dresselhas G.; Jorio A.; Advanced Topics in the Synthesis, Structure, Properties and Applications; SpringerVerlag: Berlin Heidelberg, 2008.

2. Cassel, A. M.; Raymakers, J. A.; Kong, G. J.; Dai, H.; J. Phys. Chem. B 1999, 103, 6484.

3. Hou, P. X.; Liu, C.; Cheng, H. M.; Carbon 2008, 46, 2005.

4. Suzuki, T.; Suhama, K.; Zhao, X.; Inoue, S.; Nshikawa, N.; Ando, Y.; Diamond Relat. Mater. 2007, 16, 1116.

5. Datsyuk, V.; Kalyva, M.; Papagelis, K.; Parthenios, J.; Tasis, D.; Siokou, A.; Kallitsis, I.; Galiotis, C.; Carbon 2008, 46, 833.

6. Sahoo, N. G.; Rana, S.; Cho, J. W.; Li, L.; Chan, S. H.; Prog. Polym. Sci. 2010, 35, 837.

7. Shaffer, M. S. P.; Fan, X.; Windle, A. H.; Carbon 1998, 36, 1603.

8. Ryabenko, A. G.; Dorofeeva, T. V.; Zvereva, G. I.; Carbon 2004, 42, 1523.

9. Grossiord, N.; Regev, O.; Loos, J.; Meuldijk, J.; Koning, C. E.; Anal. Chem. 2005. 77, 5135.

10. Ma, P.-C.; Siddiqui, N. A.; Maron, G.; Kim, J.-K.; Composites Part A 2010, 41, 1345.

11. Peng, X.; Wong, S. S.; Adv. Mater. 2009, 21, 625.

12. Hsin, Y. L.; Lai, J. Y.; Hwang, K. C.; Lo, S. C.; Chen, F. R.; Kai, J. J.; Carbon 2006, 44, 3328.

13. Moore, V. C.; Strano, M. S.; Haroz, E. H.; Hauge, R. H.; Smalley, R. E.; Schmidt, J.; Talmon Y.; Nano Lett. 2003, 3, 1379.

14. Vaisman, L.; Wagner, H. D.; Marom, G.; Adv. Colloid Interface Sci. 2006, 128-130, 37.

15. Krause, B.; Petzold, G.; Pegel, S.; Pötschke, P.; Carbon 2009 , 47, 602 .

16. Zhu, J.; Yudasaka, M.; Zhang, M.; Iijima, S.; J. Phys. Chem. B 2004, 108, 11317.

17. Lu, C.; Chiu, H.; Chem. Eng. J. 2008, 139, 462.

18. Salzmann, C. G.; Chu, B. T. T.; Tobias, G.; Llewellyn, S. A.; Green, M. L. H.; Carbon 2007, 45, 907.

19. Alpatova, A. L.; Shan, W.; Babica, P.; Upham, B. L.; Rogensues, A. R.; Masten, S. J.; Drownd, E.; Mohantyd, A. K.; Alociljae, E. C.; Tarabara, V. V.; Water Res. 2010, 44, 505.

20. Kharintsev, S. S.; Roffmann, G. G.; Dorozhkin, P. S.; With, G.; Loos, J.; Nanotechnology 2007, 18, 315502.

21. Bystrzejewski, M.; Huczko, A.; Lange, H.; Gemming, T.; Büchner, B.; Rümmeli, H.; J. Colloid Interface Sci. 2010, 345, 138.

22. Grossiord, N.; Regev, O.; Loos, J.; Meuldijk, J.; Koning, C. E.; Anal. Chem. 2005, 77, 5135.
23. Saito, R.; Grüneis, A.; Samsonidze, G. G.; Brar, V. W.; Dresselhaus, G.; Dresselhaus, M. S. A.; Jorio, L. G.; Cançado, C.; Fantini, M. A.; Pimenta Filho, A. G. S.; New J. Phys. 2003, $5,157$.

24. Schnitzler, M. C.; Oliveira, M. M.; Ugarte, D.; Zarbin, A. J. G.; Chem. Phys. Lett. 2003, 381, 541.

25. Araújo, A. E. P.; Duque, J. G. S.; Knobel, M.; Schnitzler, M. C.; Zarbin, A. J. G.; J. Magn. Magn. Mater. 2007, 31, 232.

26. Cava, C. E.; Possagno, R.; Schnitzler, M. C.; Roman, P. C.; Oliveira, M. M.; Lipiensky, C. M.; Roman, L.S; Zarbin, A. J. G.; Chem. Phys. Lett. 2007, 444, 304.

27. Canestraro, C. D.; Schnitzler, M. C.; Zarbin, A. J. G.; Luz, M. G. E.; Roman, L. S.; Appl. Surf. Sci. 2006, 252, 5575.

28. Oliveira, M. M.; Zarbin, A. J. G.; J. Phys. Chem. C 2008, 112, 18783.

29. Salvatierra, R. V.; Oliveira, M. M.; Zarbin, A. J. G.; Chem. Mat. 2010, $22,5222$.

30. Nossol, E.; Zarbin, A. J. G.; Adv. Funct. Mater. 2009, 19, 3980.

31. Simmons, T. J.; Bult, J.; Hashim, D. P.; Linhard, R. J.; Ajayan, P. M.; ACS Nano 2009, 3, 865.

32. Walling, C.; Acc. Chem. Res. 1975, 8, 125.

33. Bom, D.; Andrews, R.; Jacques, D.; Antony, J.; Chen, B.; Meier, M. S.; Selegue, J. P.; Nano Lett. 2002, 2, 615.

34. Osorio, A. G.; Silveira, I. C. L.; Bueno, V. L.; Bergmann, C. P.; Appl. Surf.Sci. 2008, 255, 2485.

35. Siderov, A. N.; Pabba, S.; Hewaparakrama, K. P.; Cohn, R. W.; Sumanasekera, G. U.; Nanotechnology 2008, 19, 195708.

36. Dresselhaus, M. S.; Dresselhaus, G.; Jorio, A.; Annu. Rev. Mater. Res. 2004, 34, 247.

37. Souza Filho, A. G.; Jorio, A.; Samsonidze, G. G.; Dresselhaus, G.; Saito, R.; Dresselhaus, M. S.; Nanotechnology 2003, 14, 1130.

38. Liu, Y.; Pan, C.; Wang, J.; J. Mater. Sci. 2004, 39, 1091.

39. Ago, H.; Kugler, T.; Cacaialli, F.; Salaneck, W. R.; Shaffer, M. S. P.; Windle, A. H.; Friend, R. H.; J. Phys. Chem. B 1999, 103, 116.

40. Zhang, N.; Xie, J.; Varadan, V. K.; Smart Mater. Struct. 2002, 11,962 .

41. Xia, W.; Jin, C.; Kundu, S.; Muhler, M.; Carbon 2009, 47, 919.

42. Henley, S. J.; Hatton, R. A.; Chen, G. Y.; Gao, C.; Zeng, H.; Kroto, H. W.; Silva, S. R. P.; Small 2007, 3, 1927.

Submitted: July 6, 2011

Published online: October 6, 2011 


\title{
The Effect of Different Chemical Treatments on the Structure and Stability of Aqueous Dispersion of Iron- and Iron Oxide-Filled Multi-Walled Carbon Nanotubes
}

\author{
Rodrigo A. Moraes, ${ }^{a}$ Carolina F. Matos, ${ }^{a}$ Eryza G. Castro, ${ }^{a}$ Wido H. Schreiner, ${ }^{b}$ \\ Marcela M. Oliveira ${ }^{c}$ and Aldo J. G. Zarbin ${ }^{*, a}$ \\ ${ }^{a}$ Departamento de Química and ${ }^{b}$ Departamento de Física, Universidade Federal do Paraná, \\ CP 19081, 81531-990 Curitiba-PR, Brazil
}

'Departamento Acadêmico de Química e Biologia, Universidade Tecnológica Federal do Paraná, Av. Sete de Setembro 3165, 80230-901 Curitiba-PR, Brazil

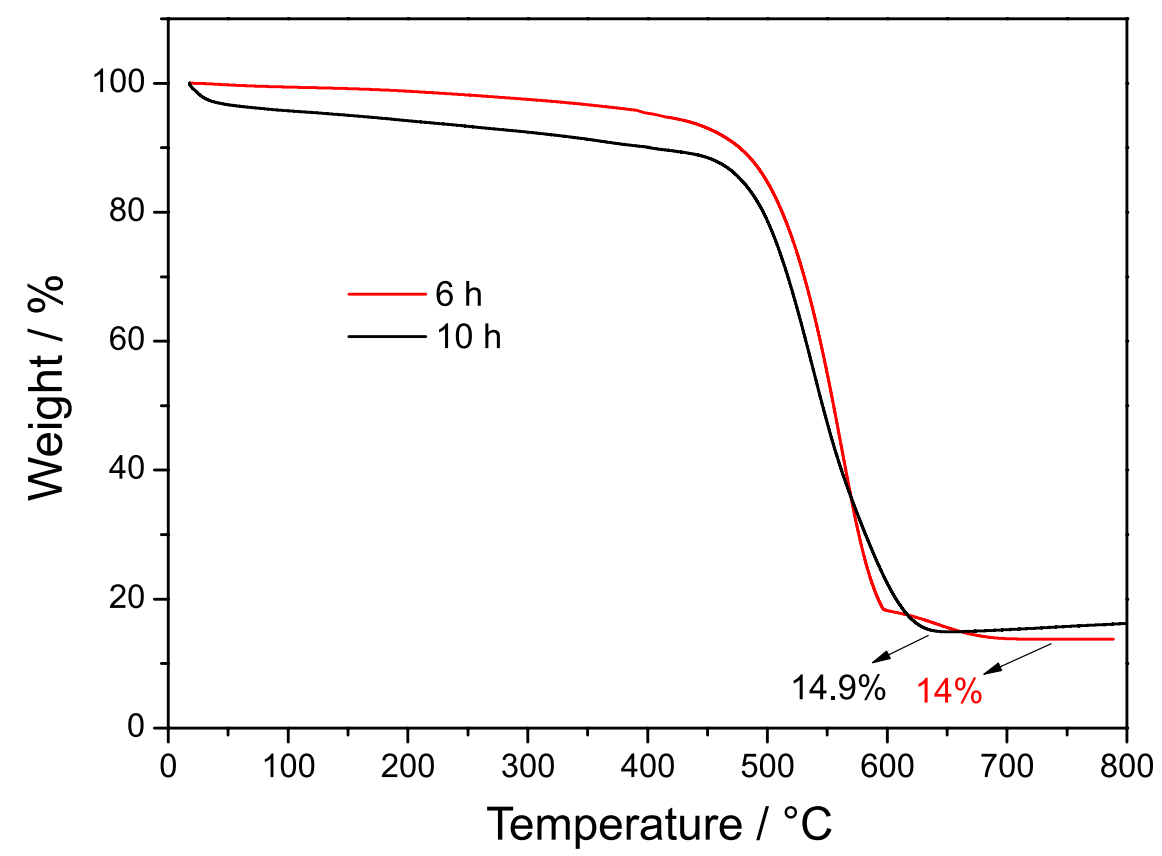

Figure S1. TG curves of carbon nanotubes after chemical treatment with a mixture of nitric + hydrochloridric acid (CNT/SA+NA) for 6 (red) and $10 \mathrm{~h}(\mathrm{black})$. 